\title{
Severe aortic complications in a patient with variant Shone's complex and bicuspid aortic valve
}

\author{
Mashrafi Ahmed, Hany Aziz, Leng Jiang
}

Department of Cardiovascular Medicine, Baystate Medical Center, Springfield, Massachusetts, USA

\section{Correspondence to} Dr. Mashrafi Ahmed, mashrafi.ahmedmd@ baystatehealth.org

Accepted 31 July 2017

\section{(1) \\ CrossMark}

To cite: Ahmed M, Aziz H, Jiang L. BMJ Case Rep Published Online First: [please include Day Month Year]. doi:10.1136/bcr-2017 221348

\section{DESCRIPTION}

A 47-year-old man presented with new onset exertional dyspnoea. He received a surgical repair of coarctation of the aorta (COA) at the age of 21 years and aortic root grafting with mechanical aortic valve replacement for type A aortic dissection and bicuspid aortic valve (BAV) at the age of 28 years. He had been otherwise healthy and did not follow-up with a cardiologist or surgeon after his last surgery. An echocardiogram (Echo) revealed normal left ventricular size and wall thickness, with an ejection fraction of $45 \%-50 \%$. There was a parachute mitral valve (MV) (figure 1), with only one severely underdeveloped lateral papillary muscle. The mechanical aortic valve was functioning normally. There was a massively dilated distal aortic arch and proximal descending aorta with maximum dimension of up to $65 \mathrm{~mm}$ (figure 2). There was no Doppler evidence of recurrent COA. The CT angiogram confirmed the giant aneurysm, which was absent from the previous site of COA repair (figure 3 ). With the current Echo finding of parachute MV and history of COA, he was diagnosed with variant Shone's complex. He then underwent a stent graft repair of the aneurysm.

Shone's complex is a rare congenital disorder consisting of four obstructive lesions of the left side of the heart which are (1) supra-MV membrane, (2) parachute MV, (3) subaortic stenosis and (4) COA. ${ }^{1}$ Since its initial reporting in $1963,{ }^{1}$ a limited number of cases had been reported in English literature. In contrast to the classic Shone's complex, incomplete forms with two or three lesions were also reported as variant or partial Shone's complex. ${ }^{1}$ Our case is a variant Shone's complex with parachute MV and COA.

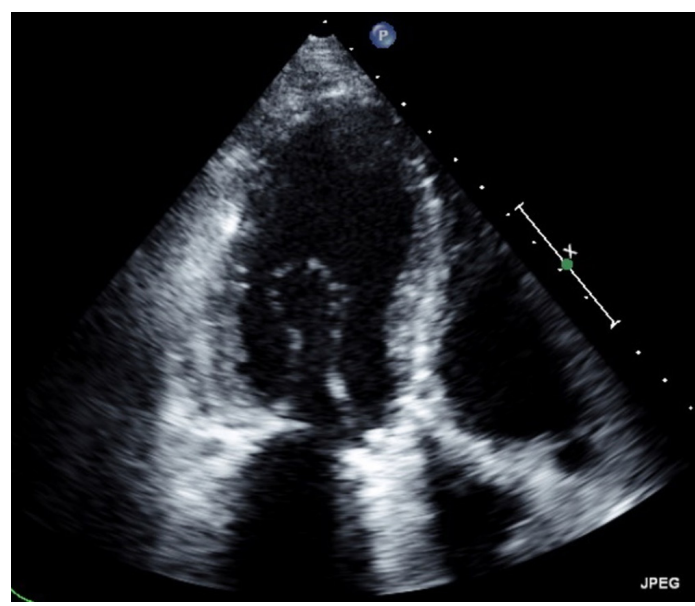

Figure 1 Echocardiographic image of parachute mitral valve.

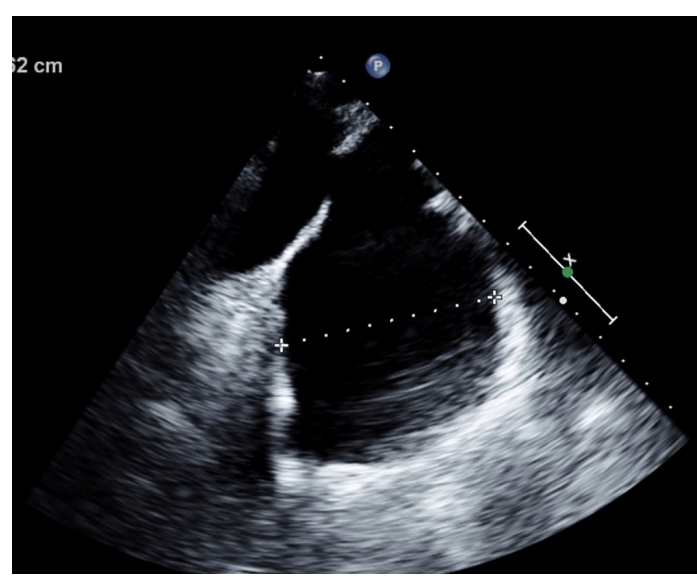

Figure 2 Echocardiographic image of dilated distal aortic arch and proximal descending aorta.

Most of the cases of Shone's complex were diagnosed during childhood with left-sided outflow obstruction with resultant downstream left heart underdevelopment. Patients were usually symptomatic during early childhood. ${ }^{2}$ Typical symptoms include dyspnoea, tachypnoea, poor feeding, failure to thrive, fatigue and signs and symptoms of heart failure and low output syndrome. Recurrent episodes of wheezing and respiratory tract infections with pulmonary congestion and acute pulmonary oedema had been reported as well. Transthoracic Echo was used as diagnostic and follow-up tool. Generally, patients with Shone's complex undergo a number of left heart interventions, both surgical and transcatheter approaches. ${ }^{3}$ COA was associated with an increased likelihood for repeat interventions. The 10-year transplant-free survival was $86 \%$. The presence of

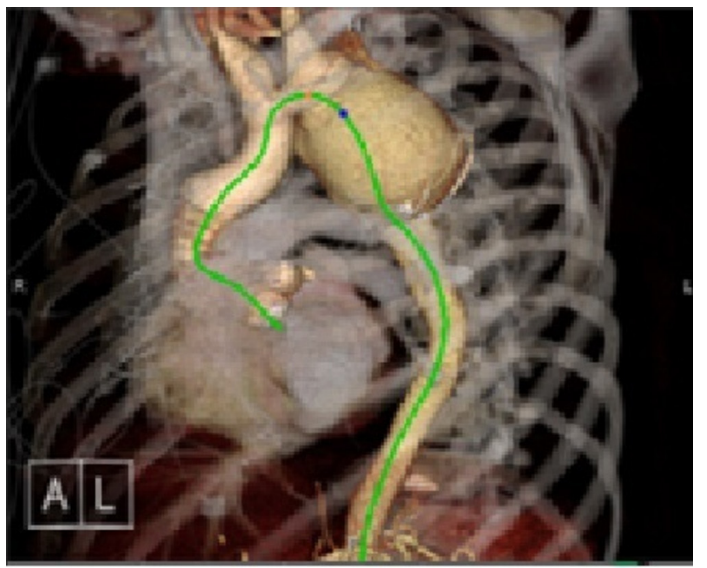

Figure 3 Three-dimensional reconstruction of CT scan image of aortic aneurysm. 
pulmonary hypertension was associated with increased mortality. Significant left heart structural growth was noticed after surgical intervention. ${ }^{3}$

In clinical practice, the definition of Shone's complex has been broadened beyond the original description. BAV has been increasingly reported in patients with Shone's complex. Since the first case series published in 1963, subsequent multiple case series reported BAV as an associated feature of Shone's complex. ${ }^{4}$ Our case emphasises that the association of BAV with Shone's complex should not be neglected since BAV is a disease

\section{Learning points}

- Shone's anomaly is a very rare congenital cardiac malformation characterised by four serial obstructive lesions of the left side of the heart, namely (1) supravalvular mitral membrane, (2) parachute mitral valve, (3) muscular or membranous subaortic stenosis and (4) coarctation of the aorta.

- Although complete Shone's complex is diagnosed relatively early in childhood, the variant form, characterised by two or three components, may remain undiagnosed owing to the variable severity of each pattern. of both the valve and the aorta. The associated aortopathy may cause severe life-threatening complications as shown in our case. Therefore, for patients with variant Shone's complex and BAV, cardiac imaging of the thoracic aorta should be performed periodically for surveillance.

Contributors MA is involved in the conception and design, acquisition of data, drafting the article and revising it critically for important intellectual content. HA is involved in the initial draft, conception and design. $\mathrm{LJ}$ is involved in the conception, design, initial drafting and approval of the final draft.

Competing interests None declared.

Patient consent Obtained.

Provenance and peer review Not commissioned; externally peer reviewed.

(C) BMJ Publishing Group Ltd (unless otherwise stated in the text of the article) 2017. All rights reserved. No commercial use is permitted unless otherwise expressly granted.

\section{REFERENCES}

1 Shone JD, Sellers RD, Anderson RC, et al. The developmental complex of "parachute mitral valve," supravalvular ring of left atrium, subaortic stenosis, and coarctation of aorta. Am J Cardiol 1963:11:714-25.

2 Subramanyan R. Mitral stenosis, supravalvular ring. http://www.emedicine.com/ped/ topic2516.htm.

3 Nicholson GT, Kelleman MS, De la Uz CM, et al. Late outcomes in children with Shone's complex: a single-centre, 20-year experience. Cardiol Young 2017;27:697-705.

4 Escárcega RO, Michelena HI, Bove AA. Bicuspid aortic valve: a neglected feature of Shone's complex? Pediatr Cardiol 2014;35:186-7.

Copyright 2017 BMJ Publishing Group. All rights reserved. For permission to reuse any of this content visit http://group.bmi.com/group/rights-licensing/permissions.

BMJ Case Report Fellows may re-use this article for personal use and teaching without any further permission.

Become a Fellow of BMJ Case Reports today and you can:

- Submit as many cases as you like

- Enjoy fast sympathetic peer review and rapid publication of accepted articles

- Access all the published articles

- Re-use any of the published material for personal use and teaching without further permission

For information on Institutional Fellowships contact consortiasales@bmjgroup.com

Visit casereports.bmj.com for more articles like this and to become a Fellow 